\title{
ANALISIS KINERJA RANTAI PASOK MENGGUNAKAN METODE BALANCED SCORECARD PADA PT. SUMBER ALFARIA TRIJAYA, TBK (ALFAMART)
}

\author{
${ }^{1}$ Dewi Siti Khadijah, ${ }^{2}$ Yolanda Rizkyta Sari, ${ }^{3}$ Qurrotul Aini \\ ${ }^{1,2,3}$ Sistem Informasi, Fakultas Sains dan Teknologi, UIN Syarif Hidayatullah Jakarta, \\ Jl. Ir H. Juanda No.95, Cempaka Putih, Ciputat Timur, Tangerang Selatan 15412, Banten \\ Email:dewisiti.khaadjh17@mhs.uinjkt.ac.id, yolanda.rizkyta17@mhs.uinjkt.ac.id, \\ qurrotul.aini@uinjkt.ac.id.
}

(Diterima:1 Januari 2020, direvisi:22 April 2020, disetujui:28 April 2020 )

\begin{abstract}
Along with the development of the retail business, it is no longer managed traditionally, but in a modern way so that it becomes an innovative, dynamic, and competitive business. PT. Sumber Alfaria Trijaya, Tbk (Alfamart) is one of the retail businesses engaged in minimarket, which has grown to become one of the leading companies in the retail business. One effort to meet customer needs is to pay attention to supply chain management properly because supply chain management basically pays attention to how the goods process gets into the hands of customers properly. The purpose of this research is to find out and analyze supply chain flow and performance, with the analytical method used is a balanced scorecard. The balanced scorecard translates a vision, mission, and strategy of the company into the determination of goals and scorecard size, and it completes a set of financial measures of past performance with measures of drivers for future performance. The results of the average assessment recap with the balanced scorecard show that from a financial perspective it gets a value of 4 (good), an internal business process perspective gets a value of 4.15 (very good), a growth and development perspective gets a value of 3.8 (good), and a customers' perspective gets a value of 3.56 (good). It can be concluded that the performance of the supply chain at PT. Sumber Alfaria Trijaya, Tbk is already good, but still needs to be improved in order to be better.
\end{abstract}

Keywords: Supply Chain, Balanced Scorecard, Alfamart.

\begin{abstract}
ABSTRAK
Seiring dengan perkembangan bisnis ritel, pada saat ini bisnis ritel tidak lagi dikelola secara tradisional, melainkan dengan cara modern sehingga menjadi bisnis yang inovatif, dinamis, dan kompetitif. PT. Sumber Alfaria Trijaya, Tbk (Alfamart) merupakan salah satu bisnis retail yang bergerak dibidang minimarket, yang tumbuh menjadi salah satu perusahaan terdepan dalam usaha ritel. Salah satu upaya untuk memenuhi kebutuhan pelanggan adalah dengan memerhatikan manajemen rantai pasok dengan baik, karena manajemen rantai pasok pada dasarnya memperhatikan bagaimana proses barang sampai ke tangan pelanggan dengan baik. Tujuan dilakukannya penelitian ini adalah untuk mengetahui dan menganalisis aliran dan kinerja rantai pasok, dengan metode analisis yang digunakan adalah balanced scorecard. Balanced scorecard menerjemahkan sebuah visi, misi, dan strategi dari perusahaan ke dalam penentuan tujuan dan ukuran scorecard, balanced scorecard melengkapi seperangkat ukuran finansial kinerja masa lalu dengan ukuran pendorong (drivers) kinerja masa depan. Hasil rekap penilaian rata-rata dengan balanced scorecard menunjukkan bahwa dari perspektif keuangan mendapatkan nilai 4 (baik), perspektif proses bisnis internal mendapatkan nilai 4,15 (sangat baik), perspektif pertumbuhan dan pengembangan mendapatkan nilai 3,8 (baik), dan perspektif pelanggan mendapatkan nilai 3,56 (baik). Dapat disimpulkan bahwa kinerja rantai pasok di PT. Sumber Alfaria Trijaya, Tbk sudah baik, namun masih harus ditingkatkan agar menjadi lebih baik.
\end{abstract}

Kata Kunci: Rantai Pasok, Balanced Scorecard, Alfamart. 


\section{PENDAHULUAN}

Seiring dengan perkembangan bisnis ritel, pada saat ini bisnis ritel tidak lagi dikelola secara tradisional, melainkan dengan cara modern sehingga menjadi bisnis yang inovatif, dinamis, dan kompetitif. Retail adalah usaha yang menjual produk/barang kebutuhan rumah tangga, termasuk produk kebutuhan sehari-hari yang menggunakan sistem swalayan (konsumen mengambil produk/barang itu sendiri tanpa ada pramuniaga yang melayani). Salah satu jenis bisnis retail yaitu minimarket, minimarket merupakan bisnis retail yang menjual barang kebutuhan sehari-hari dan menawarkan kemudahan karena lokasi yang terjangkau dan dekat dengan konsumen serta mengutamakan kepraktisan dan kecepatan yang didukung dari luas toko yang tidak terlalu besar sehingga konsumen dapat berbelanja dengan waktu yang tidak terlalu lama.

PT. Sumber Alfaria Trijaya, Tbk (Alfamart) merupakan salah satu bisnis retail yang bergerak dibidang minimarket, yang tumbuh menjadi salah satu perusahaan terdepan dalam usaha ritel dengan melayani lebih dari 4 juta pelanggan setiap harinya di lebih dari 13.000 gerai yang tersebar di Indonesia dan didukung lebih dari 90.000 karyawan[1]. PT. Sumber Alfaria Trijaya, Tbk (Alfamart) adalah satu dari beberapa perusahaan ritel yang sukses serta bersaing ketat dan sehat untuk memenuhi kebutuhan pasar yang ada di seluruh Indonesia.

Salah satu persaingan dalam bisnis retail ini adalah berlomba dalam mempertahankan loyalitas konsumen terhadap perusahaan yang berkaitan dengan kinerja perusahaan itu sendiri. Kinerja merupakan suatu istilah secara umum yang digunakan untuk sebagian atau seluruh tindakan atau aktivitas dari suatu organisasi pada suatu periode dengan referensi pada jumlah standar seperti biayabiaya masa lalu atau yang diproyeksikan, dengan dasar efisiensi, pertanggungjawaban atau akuntabilitas manajemen dan semacamnya, sedangkan kinerja perusahaan adalah suatu tampilan keadaan secara utuh atas perusahaan selama periode waktu tertentu, merupakan hasil atau prestasi yang dipengaruhi oleh kegiatan operasional perusahaan dalam memanfaatkan sumber-sumber daya yang dimiliki[2], sedangkan pengukuran kinerja adalah tindakan pengukuran yang dilakukan terhadap berbagai aktivitas dalam rantai nilai pasokan yang ada pada perusahaan[3].

Maka dari itu diperlukan manajemen rantai pasokan yang baik agar seluruh aktivitas dalam perusahaan dapat berjalan dengan baik. Manajemen rantai pasokan adalah suatu konsep atau mekanisme untuk untuk meningkatkan produktivitas total perusahaan dalam rantai supplai melalui optimalisasi waktu, lokasi dan aliran kuantitas bahan. Oleh karena itu, dalam dunia bisnis maka perusahaan harus meningkatkan efisiensi proses logistik[4]. Manajemen Rantai pasok (Supply chain management) adalah sebuah 'proses payung' di mana produk diciptakan dan disampaikan kepada konsumen dari sudut struktural[5]. Sebuah supply chain (rantai pasok) merujuk kepada jaringan yang rumit dari hubungan yang mempertahankan organisasi dengan rekan bisnisnya untuk mendapatkan sumber produksi dalam menyampaikan kepada konsumen. Manajemen Rantai Pasokan menggambarkan koordinasi dari keseluruhan kegiatan rantai pasokan, dimulai dari bahan baku dan diakhiri dengan pelanggan yang puas. Rantai pasokan mencakup pemasok hingga perusahaan manufaktur dan/atau penyedia jasa; dan perusahaan distributor, grosir dan/atau pengecer yang mengantarkan produk dan/atau jasa ke konsumen akhir[6].

Tujuan dari setiap rantai pasok yaitu untuk memaksimalkan nilai yang dihasilkan secara keseluruhan berdasarkan beberapa aspek yang ada didalam perusahaan[7] sedangkan tujuan lainnya ialah memastikan material terus mengalir dari sumber ke konsumen akhir. Bagian-bagian yang bergerak di dalam rantai pasok haruslah berjalan secepat mungkin. Dan dengan tujuan mencegah terjadinya penumpukan inventori di satu lokal, arus ini haruslah diatur sedemikian rupa agar bagianbagian tersebut bergerak dalam koordinasi yang teratur. Istilah yang sering digunakan ialah synchronous[8].

Dengan memerhatikan manajemen rantai pasok dengan baik itu menjadi salah satu upaya untuk memenuhi kebutuhan pelanggan, karena manajemen rantai pasok pada dasarnya memperhatikan bagaimana proses barang sampai ke tangan pelanggan dengan baik, selain itu dibutuhkan juga kualitas pelayanan yang baik terhadap fasilitas yang diberikan kepada pelanggan. Manajemen rantai pasok meliputi manajemen yang dilakukan oleh perusahaan serta kinerja dari perusahaan tersebut[4].

Salah satu merode yang ada untuk mengukur kinerja suatu perusahaan ialah metode Balanced scorecard. Balanced scorecard merupakan alat pengukur kinerja eksekutif yang memerlukan ukuran komprehensif dengan empat perspektif, yaitu perspektif keuangan, perspektif pelanggan, perspektif bisnis internal, dan perspektif pertumbuhan dan pembelajaran[9]. Balanced scorecard menerjemahkan 
sebuah visi, misi, dan strategi dari perusahaan ke dalam penentuan tujuan dan ukuran scorecard, balanced scorecard melengkapi seperangkat ukuran finansial kinerja masa lalu dengan ukuran pendorong (drivers) kinerja masa depan. Tujuan dan ukuran scorecard diturunkan dari visi dan strategi[10].

Tujuan dari penelitian ini adalah untuk menganalisis rantai pasok yang didapatkan di PT. Sumber Alfaria Trijaya, Tbk (Alfamart) cabang Ciputat di Jalan W.R Supratman sebagai tempat observasi untuk menganalisis rantai pasokan pada salah satu cabang PT. Sumber Alfaria Trijaya, Tbk (Alfamart). Metode penelitian yang digunakan adalah metode kuantitatif dan teknik pengumpulan datanya menggunakan studi literatur dan studi lapangan. Studi lapangan berupa observasi, wawancara dan dokumentasi. Dalam menganalisis rantai pasok metode balance scorecard sebagai tolak ukurnya, metode balance scorecard dimaksudkan untuk menjawab pertanyaan pokok, yaitu[9]:

a. Bagaimana penampilan perusahaan dimata para pemegang saham? (perspektif keuangan)

b. Bagaimana pandangan para pelanggan terhadap perusahaan? (perspektif pelanggan)

c. Apa yang menjadi keunggulan perusahaan? (perspektif bisnis internal)

d. Apa perusahaan harus terus menerus melakukan perbaikan dan menciptakan nilai secara berkesinambungan? (perspektif pertumbuhan dan pembelajaran)

\section{TINJAUAN PUSTAKA}

Beberapa penelitian yang dilakukan sebelumnya ada analisis rantai pasok pada PT.Kemfood Cabang Kota Bandung, dalam penelitian tersebut digunakan metode studi kasus dan balance scorecard untuk pengukuran kinerja dari rantai pasok perusahaan tersebut, yang hasilnya menunjukkan aliran rantai pasok dari produsen sebagian besar langsung ke konsumen dan mengukur kinerja rantai pasok untuk perspektif bisnis internal[11]. Manajemen rantai pasokan adalah sebuah sistem yang melibatkan proses produksi, pengiriman, penyimpanan, distribusi dan penjualan produk dalam rangka memenuhi permintaan akan produk tersebut rantai pasokan didalamnya termasuk seluruh proses dan kegiatan yang terlibat didalam penyampaian produk tersebut sampai ke tangan pemakai konsumen. Semua itu termasuk proses produksi pada manufaktur, sistem transportasi yang menggerakan produk dari manufaktur sampai ke outlet retail, gudang tempat penyimpanan produk tersebut, pusat distrubusi tempat dimana pengiriman dalam lusin besar dibagi kedalam lusin kecil untuk dikirim kembali ke toko-toko dan akhirnya sampai ke pengecer yang menjual produk tersebut. Sebuah operasi yang efisien dari rantai pasokan tergantung lengkap dan akuratnya aliran data yang berhubungan dengan produk yang diminta dari pengecer sampai pelanggan. Metode analisis yang digunakan adalah mengunakan metode balanced scorecard analisis rantai pasokan dari awal sampai akhir dengan proses aktivitas pengadaan bahan baku, menjadi barang setengah jadi dan produk akhir serta pengiriman ke pelanggan. Hasil penelitian ditemukan bahwa petani masih menggunakan alat tradisional, hal ini tidak efisien serta banyak mengorbankan waktu dan biaya[12].

Dalam penelitian yang lain dilakukan penelitian analisis pengukuran kinerja CV MCH Sidoardjo yang meneliti kinerja perusahaan dalam perspektif keuangan (ROE, ROI, SG, ROA), pelanggan (customer acquition, customer satisfaction, on time delivery), proses bisnis internal (kerusakan peralatan, kecelakaan kerja) serta pembelajaran dan pertumbuhan (employee turnover, produktifitas, kepuasan karyawan)[13]. Sedangkan dalam penelitian lain mengambil pengukuran kinerja manajemen rantai pasok pada perspektif keuangan seperti pengelolaan uang serta aset pemerintah menggunakan metode balanced scorecard karena metode tersebut dapat menilai dan mengukur kinerja secara efektif dan komprehensif[14].

Berdasarkan penelitian yang sudah dilakukan sebelumnya membuktikan metode balanced scorecard efektif dalam mengukur suatu kinerja rantai pasok di dalam suatu perusahaan, dan aspek yang di analisis dalam metode balanced scorecard mencakup aspek-aspek yang lengkap dibandingkan dengan metode yang lain. Dalam penelitian ini metode balanced scorecard digunakan sebagai tolak ukur kinerja perusahaan dengan penilaiannya menggunakan skala likert, dan menggunakan Weight Means Score dalam perhitungannya. 


\section{METODE PENELITIAN}

3.1 Lokasi dan Waktu Penelitian

Pelaksanaan penelitian ini dilakukan pada PT. Sumber Alfaria Trijaya, Tbk (Alfamart) cabang Ciputat di Jalan W.R Supratman. Waktu pelaksanaan penelitian ini secara keseluruhan dilaksanakan pada tanggal 20 November 2019 hingga 20 Desember 2019.

\subsection{Teknik Pengumpulan Data}

Data yang digunakan serta sumber dalam penelitian ini ialah sebagai berikut:

a. Data Primer

Data primer adalah data yang diambil senantiasa dibutuhkan untuk digunakan dalam penelitian ini yang diperoleh langsung dari hasil pengamatan langsung dan wawancara di lapangan. Dalam penelitian yang dilakukan dilapangan (field reaserch). Ada beberapa hal yang dilakukan seperti:

1) Observasi, pengamatan dilakukan pada tanggal 10 November 2019 yang dilakukan secara langsung dengan mengunjungi alfamart W.R Supratman.

2) Wawancara, pengumpulan data dengan melakukan tanya jawab secara langsung kepada kepala toko Alfamart cabang Ciputat seputar manajemen rantai pasok yang terdapat pada Alfamart cabang Ciputat.

3) Kuesioner, yang merupakan sejumlah pertanyaan tertulis yang diberikan kepada pegawai toko dan kepada konsumen Alfamart cabang Ciputat yang bertujuan untuk mendapatkan informasi mengenai manajemen rantai pasok yang ada yang di Alfamart cabang Ciputat.

b. Data Sekunder

Data sekunder yang digunakan dalam penulisan ini ialah literatur, artikel, jurnal serta situs di internet yang berkenaan dengan penelitian yang digunakan sebagai data penunjang dalam penelitian ini. Data sekunder diambil seiring dengan berjalannya penulisan jurnal ini.

\subsection{Langkah-Langkah Penelitian}

Secara sistematis tahapan yang dilakukan dalam penelitian ini seperti Gambar 1:

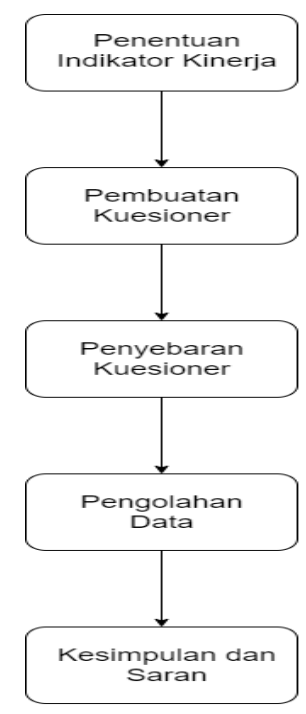

\section{Gambar 1 Tahapan penelitian}

a. Penentuan Indikator Kinerja

Dalam menentukan indikator kinerja, penulis terlebih dahulu melakukan brainstorming.

b. Pembuatan Kuesioner

Pada tahap ini, indikator kinerja yang diperoleh dari kegiatan brainstorming kemudian disusun berupa pertanyaan berdasarkan pengukuran kinerja Balance Scorecard yang berdasarkan kepada 4 perspektif pengukuran yaitu keuangan, bisnis internal, pertumbuhan dan perkembangan, serta pelanggan. 
c. Penyebaran Kuesioner

Kuesioner diberikan kepada 1 orang kepala cabang, 3 orang pegawai, dan 5 orang pelanggan PT. Sumber Alfaria Trijaya, Tbk dengan total 9 orang responden.

d. Pengolahan Data

Pada tahap ini, dilakukan pengolahan data dari hasil kuesioner yang dibobotkan dengan skala likert yang telah disebarkan kepada responden.

Skala likert (Likert scale) adalah skala respon psikometri terutama digunakan dalam kuesioner untuk mendapatkan preferensi responden atas sebuah pernyataan atau serangkaian laporan. Skala likert digunakan untuk mengukur sikap, pendapat, dan persepsi seseorang atau sekelompok orang tentang kejadian atau gejala sosial. Dalam penelitian gejala sosial, peneliti telah memenntukan secara spesifik skalanya dan selanjutnya disebut variabel penelitian[17]. Skala pengukuran variabel dalam penelitian ini mengacu pada Skala likert (Likert scale), dimana masing-masing dibuat dengan menggunakan skala 1-5 kategori jawaban, yang masing-masing jawaban diberi nilai (score) atau bobot yaitu banyaknya score antara 1 sampai 5 , dengan rincian seperti pada Tabel 1 .

Tabel 1 Tabel Nilai[18]

\begin{tabular}{cccccc}
\hline PK & STS & TS & RR & S & SS \\
\hline Nilai & 1 & 2 & 3 & 4 & 5 \\
\hline
\end{tabular}

Berdasarkan Tabel 1 dapat diketahui bahwa pertanyaan kuesioner (PK), sangat tidak setuju (STS), tidak setuju (TS), ragu-ragu (RR), setuju (S) dan sangat setuju (SS).

e. Perhitungan nilai bobot

Dihitung nilai bobot untuk masing masing indikator kinerja dan kemudian dilakukan perhitungan terhadap skor pencapaian kinerja perusahaan secara keseluruhan dengan menggunakan metode weight means score. Berdasarkan perhitungan tersebut, dapat diidentifikasi apakah tercapai atau sudah tercapainya target dari indikator kinerja perusahaan.

Untuk memperoleh penafsiran atau interpretasi digunakan analisis Weight Means Score $(M)$, dengan persamaan sebagai berikut[19].

$$
\mathrm{M}=\frac{\sum f_{i} x_{i}}{n}
$$

Dimana berdasarkan persamaan 1 dapat diketahui bahwa perolehan angka penafsiran $(M)$, frekuensi $\left(f_{i}\right)$, pembobotan skala nilai skor $\left(x_{i}\right)$, penjumlahan $\left(\sum\right)$, dan jumlah responden $(n)$. Setelah perhitungan dilakukan dengan persamaan tersebut lalu hasilnya ditafsirkan oleh keterangan dan nilai skor yang ada pada Tabel 2.

\begin{tabular}{|c|c|c|}
\hline No & Nilai Skor & Keterangan \\
\hline 1 & $1,00-1,80$ & Tidak Baik \\
\hline 2 & $1,81-2,60$ & Kurang Baik \\
\hline 3 & $2,61-3,40$ & Cukup Baik \\
\hline 4 & $3,41-4,20$ & Baik \\
\hline 5 & $4,21-5,00$ & Sangat Baik \\
\hline
\end{tabular}

f. Kesimpulan dan Saran

Kesimpulan dan saran didapatkan dari hasil pengolahan data terhadap pengukuran kinerja rantai pasok pada PT. Sumber Alfaria Trijaya, Tbk.

\section{HASIL DAN PEMBAHASAN}

\section{1 Narasumber}

PT. Sumber Alfaria Trijaya, Tbk (Alfamart) cabang Ciputat di Jalan W.R Supratman yang merupakan salah satu Alfamart yang tergolong memiliki pendapatan yang tinggi karena lokasinya yang strategis terletak di salah satu jalan utama yang berada di Ciputat. PT. Sumber Alfaria Trijaya, Tbk (Alfamart) cabang Ciputat di Jalan W.R Supratman buka mulai pukul 08.00 WIB hingga pukul 22.00 WIB. Karyawan dibagi menjadi 2 shift kerja dalam melayani konsumen, yang dimana masing- 
masing shift terdiri dari 3 orang karyawan. Dalam melakukan penelitian ini peneliti melakukan wawancara kepada beberapa pihak, seperti:

a. Kepala Cabang

Informan yang bernama Bapak Andriansyah, informasi yang didapatkan dari kepala cabang/kepala toko ini ialah mengenai kegiatan apa saja yang dilaksanakan di PT. Sumber Alfaria Trijaya, Tbk (Alfamart) cabang Ciputat di Jalan W.R Supratman.

b. Divisi Kasir

Informan yang memberikan informasi mengenai sistem keuangan yang berjalan, mengenai pertanyaan-pertanyaan umum dan tidak mengambil data yang merupakan privasi perusahaan.

c. Divisi Gudang

Informan yang memberikan informasi mengenai pengiriman barang dari pusat ke cabang, mengenai pencatatan gudang, ketersediaan barang dan segala sesuatu yang mengenai tentang penyimpanan.

\section{2 Hasil Kuesioner}

Hasil kuesioner yang menggunakan metode balanced scorecard dan diolah menggunakan skala likert. Pengukuran kinerja manajemen rantai pasok diukur menggunakan kuesioner yang ditinjau dari beberapa perspektif balanced scorecard, yaitu:

a. Perspektif Keuangan

Perspektif keuangan merupakan salah satu bagian dari rantai pasok yang mengurusi tentang kuangan suatu perusahaan, pada PT. Sumber Alfaria Trijaya, Tbk (Alfamart) cabang Ciputat di Jalan W.R Supratman. Keuangan pada cabang ini cenderung stabil setiap harinya, hal tersebut dipengaruhi dengan lokasi retail yang terletak dipinggir jalan yang menjadi salah satu jalan utama yang ada di Ciputat. Berdasarkan penjelasan diatas didapatkan scorecard perspektif keuangan yang dijelaskan pada Tabel 3 berikut.

Tabel 3 Scorecard Perspektif Keuangan Rantai Pasok PT. Sumber Alfaria Trijaya, Tbk (Alfamart) cabang Ciputat di Jalan W.R Supratman

\begin{tabular}{|c|c|c|c|}
\hline No & Tujuan & Ukuran & Target \\
\hline \multirow[t]{3}{*}{1} & Tingkat Profitabilitas & Profit margin & $\begin{array}{l}\text { Mengantisipasi penurunan } \\
\text { jumlah laba kotor dengan } \\
\text { menetapkan target laba dan } \\
\text { pendapapatan secara periodik }\end{array}$ \\
\hline & & Ketetapan alokasi modal & $\begin{array}{l}\text { Meningkatkan efisiensi biaya } \\
\text { dengan melakukan kegiatan } \\
\text { operasional dengan biaya yang } \\
\text { paling efisien }\end{array}$ \\
\hline & & Produktivitas modal & $\begin{array}{l}\text { Perusahaan mengalami } \\
\text { peningkatan pendapatan dalam } \\
\text { setiap tahunnya }\end{array}$ \\
\hline 2 & Tingkat likuiditas & Siklus cash-to-cash & $\begin{array}{l}\text { Membuat laporan keuangan } \\
\text { penjualan kasir setiap harinya }\end{array}$ \\
\hline
\end{tabular}

b. Perspektif Proses Bisnis Internal

Perspektif proses bisnis internal mengidentifikasi manajemen perusahaan mengenai proses-proses bisnis yang ada untuk memenuhi dan memuaskan kebutuhan konsumen, berbagai promosi potongan harga di setiap bulan merupakan salah satu teknik marketing yang digunakan untuk bertahan dipersaingan antar sesama retail sejenisnya. Berdasarkan penjelasan diatas didapatkan scorecard perspektif proses bisnis internal yang dijelaskan pada Tabel 4 berikut. 
Tabel 4 Scorecard Perspektif Proses Bisnis Internal Rantai Pasok PT. Sumber Alfaria Trijaya, Tbk (Alfamart) cabang Ciputat di Jalan W.R Supratman

\begin{tabular}{|c|c|c|c|}
\hline No & Tujuan & Ukuran & Target \\
\hline 1 & Efisiensi Operasi & $\begin{array}{l}\text { Implementasi modal } \\
\text { rantai pasok } \\
\text { Penerapan operasional }\end{array}$ & $\begin{array}{l}\text { Aktivitas operasional perusahaan selalu } \\
\text { disesuaikan dengan target biaya, waktu } \\
\text { dan kualitas } \\
\text { Aktivitas operasi perusahaan disesuaikan } \\
\text { dengan teknologi baru }\end{array}$ \\
\hline 2 & $\begin{array}{l}\text { Pengembangan } \\
\text { Perusahaan }\end{array}$ & $\begin{array}{l}\text { Peningkatan kinerja } \\
\text { perusahaan }\end{array}$ & $\begin{array}{l}\text { Terlaksananya aktivitas research and } \\
\text { development oleh perusahaa } \\
\text { Terlaksanannya evaluasi dan perbaikan } \\
\text { berkelanjutan disetiap operasi }\end{array}$ \\
\hline
\end{tabular}

c. Perspektif Pembelajaran dan Pertumbuhan

Perspektif pembelajaran dan pertumbuhan mengenai faktor-faktor yang mempengaruhi kinerja yang berhubungan dengan Sumber Daya Manusia (SDM). Faktor-faktor tersebut berupa kegiatan yang menunjang kinerja dari perusahaan sehingga adanya pertumbuhan pada perusahaan tersebut. Berdasarkan penjelasan diatas didapatkan scorecard perspektif pembelajaran dan pertumbuhan yang dijelaskan pada Tabel 5 berikut.

Tabel 5 Scorecard Perspektif Pembelajaran dan Pertumbuhan Rantai Pasok PT. Sumber Alfaria Trijaya, Tbk (Alfamart) cabang Ciputat di Jalan W.R Supratman

\begin{tabular}{|c|c|c|c|}
\hline No & Tujuan & Ukuran & Target \\
\hline \multirow[t]{3}{*}{1} & $\begin{array}{l}\text { Kapabilitas } \\
\text { SDM }\end{array}$ & $\begin{array}{l}\text { Meningkatkan SDM yang } \\
\text { dimiliki perusahaan }\end{array}$ & $\begin{array}{l}\text { Dilakukan pelatihan dan pendidikan bagi } \\
\text { setiap karyawan secara berkala dan } \\
\text { mengadakan seminar untuk karyawan } \\
\text { secara berkala }\end{array}$ \\
\hline & & Menerapkan program & Program kompensasi diberikan untuk \\
\hline & & kompensasi & $\begin{array}{l}\text { karyawan berprestasi setiap bulannya } \\
\text { sebafai apresiasi }\end{array}$ \\
\hline 2 & $\begin{array}{l}\text { Kapabilitas } \\
\text { Informasi }\end{array}$ & Aliran informasi & $\begin{array}{l}\text { Perusahaan memberikan kemudahan } \\
\text { mengakses informasi yang terbatas } \\
\text { kepada karyawannya untuk memudahkan } \\
\text { operasi perusahaan }\end{array}$ \\
\hline 3 & $\begin{array}{l}\text { Kapabilitas } \\
\text { perusahaan }\end{array}$ & Operasional & $\begin{array}{l}\text { Memperhatikan dan menyediakan fasilitas } \\
\text { untuk mendukung pekerjaan setiap } \\
\text { karyawannya }\end{array}$ \\
\hline
\end{tabular}

d. Perspektif Pelanggan

Perspektif pelanggan mengidentifikasi bagaimana kondisi konsumen dengan segmen pasar yang telah dipilih oleh perusahaan untuk bersaing dengan kompetitor. Segmen yang telah dipilih mencerminkan keberadaan konsumen sebagai sumber pendapatan. Berdasarkan penjelasan diatas didapatkan scorecard perspektif pelanggan yang dijelaskan pada Tabel 6 berikut. 
Tabel 6 Scorecard Perspektif Pelanggan Rantai Pasok PT. Sumber Alfaria Trijaya, Tbk (Alfamart) cabang Ciputat di Jalan W.R Supratman

\begin{tabular}{|c|c|c|c|}
\hline No & Tujuan & Ukuran & Target \\
\hline 1 & Kualitas Barang & $\begin{array}{l}\text { Kepuasan terhadap kualitas } \\
\text { barang yang dijual oleh } \\
\text { perusahaan }\end{array}$ & $\begin{array}{l}\text { Membuat pelanggan } \\
\text { puas akan barang } \\
\text { yang dijual oleh } \\
\text { perusahaan }\end{array}$ \\
\hline 2 & Kualitas Layanan & Kejelasan perusahaan & $\begin{array}{l}\text { Langsung ditangani } \\
\text { oleh perusahaan } \\
\text { dengan respon yang } \\
\text { cepat } \\
\text { Informasi tentang jasa } \\
\text { yang diberikan } \\
\text { perusahaan dapat } \\
\text { diakses dan diketahui } \\
\text { dengan mudah oleh } \\
\text { pelanggan }\end{array}$ \\
\hline 3 & Kualitas Harga & Kepuasan terhadap harga & $\begin{array}{l}\text { Membuat pesaingan } \\
\text { harga antar retail } \\
\text { sejenis untuk } \\
\text { menekan penjualan, } \\
\text { dan membuat } \\
\text { pelanggan puas } \\
\text { dengan harga yang } \\
\text { ditawarkan }\end{array}$ \\
\hline
\end{tabular}

Dalam penelitian ini kuesioner digunakan sebagai alat bantu untuk pengumpulan data yang diisi oleh informan, informan yang dimaksud ialah pimpinan cabang/kepala toko, divisi kasir, divisi gudang, serta pelanggan Alfamart cabang Ciputat untuk perspektif pelanggan. Total sampel pegawai Alfamart ialah 4 orang dan sampel pelanggan sebanyak 5 orang.

\section{3 Perhitungan Nilai Bobot}

Perhitungan nilai bobot dilakukan dengan menggunakan rumus Weight Mean Score (M) berdasarkan data yang sudah didapatkan dari kuesioner sebelumnya. Maka didapatkan data karakteristik responden perspektif keuangan yang dijelaskan pada Tabel 7 dan perhitungan bobot untuk perspektif keuangan pada Tabel 8.

Tabel 7 Data Karakteristik Responden Perspektif Keuangan

\begin{tabular}{cccccc}
\hline Responden & P1 & P2 & P3 & P4 & P5 \\
\hline 1 & 4 & 5 & 3 & 5 & 5 \\
2 & 4 & 3 & 4 & 3 & 4 \\
3 & 4 & 3 & 4 & 3 & 4 \\
4 & 4 & 5 & 3 & 4 & 5 \\
\hline
\end{tabular}

Tabel 8 Perhitungan Bobot Persfektif Keuangan

\begin{tabular}{cc}
\hline Pertanyaan & Nilai B \\
\hline 1 & 4 \\
2 & 4 \\
3 & 3,5 \\
4 & 4 \\
5 & 4,5
\end{tabular}

Setelah menghitung bobot setiap pertanyaan dari semua perspektif didapatkan hasil perhitungan seperti pada Tabel 9 . 
Tabel 9 Rata-rata Skor Serta Pertanyaan Kuesioner Rantai Pasok PT. Sumber Alfaria Trijaya, Tbk (Alfamart) cabang Ciputat di Jalan W.R Supratman

\begin{tabular}{|c|c|c|c|c|}
\hline No & Perspektif & Pertanyaan & Skor & Kriteria \\
\hline \multirow[t]{6}{*}{1} & Keuangan & $\begin{array}{l}\text { Perusahaan selalu menetapkan } \\
\text { target laba dan pendapatan secara } \\
\text { periodic }\end{array}$ & 4 & Baik \\
\hline & & $\begin{array}{l}\text { Perusahaan selalu melakukan } \\
\text { kegiatan operasinya dengan biaya } \\
\text { yang paling efisien }\end{array}$ & 4 & Baik \\
\hline & & $\begin{array}{l}\text { Pendapatan perusahaan mengalami } \\
\text { peningkatan tiap tahunnya }\end{array}$ & 3,5 & Baik \\
\hline & & $\begin{array}{l}\text { Pengalokasian modal kerja selalu } \\
\text { sesuai dengan yang diharapkan }\end{array}$ & 4 & Baik \\
\hline & & Laporan keuangan selalu dilaporkan perharinya & 4,5 & Sangat Bik \\
\hline & Total Rata-Rata & & 4 & Baik \\
\hline \multirow[t]{6}{*}{2} & $\begin{array}{l}\text { Proses Bisnis } \\
\text { Internal }\end{array}$ & $\begin{array}{l}\text { Dilaksanakan aktivitas research and development oleh } \\
\text { perusahaan }\end{array}$ & 4 & Baik \\
\hline & & $\begin{array}{l}\text { Proses operasi perusahaan disesuaikan dengan teknologi } \\
\text { baru }\end{array}$ & 4 & Baik \\
\hline & & $\begin{array}{l}\text { Aktivitas operasi perusahaan selalu disesuaikan dengan } \\
\text { target biaya, waktu dan kualitas }\end{array}$ & 4 & Baik \\
\hline & & $\begin{array}{l}\text { Dilaksanakan evaluasi dan perbaikan berkelanjutan di tiap } \\
\text { kegiatan operasi }\end{array}$ & 4 & Baik \\
\hline & & Dilaksanakan pelayanan purna jual oleh perusahaan & 4,75 & Sangat Baik \\
\hline & Total Rata-Rata & & 4,15 & Sangat Baik \\
\hline \multirow[t]{6}{*}{3} & $\begin{array}{l}\text { Pembelajaran } \\
\text { dan } \\
\text { Pertumbuhan }\end{array}$ & $\begin{array}{l}\text { Perusahaan selalu memperhatikan dan menyediakan } \\
\text { fasilitas untuk mendukung pekerjaan setiap karyawan }\end{array}$ & 4,25 & Sangat Baik \\
\hline & & $\begin{array}{l}\text { Program kompensasi diberikan untuk menunjang apresiasi } \\
\text { karyawan berprestasi }\end{array}$ & 4 & Baik \\
\hline & & $\begin{array}{l}\text { Karyawan diberikan kemudahan untuk mengakses } \\
\text { informasi yang dibutuhkan }\end{array}$ & 3,5 & Baik \\
\hline & & Perusahaan mengadakan pelatihan dan pendidikan & 3,75 & Baik \\
\hline & & $\begin{array}{l}\text { Perusahaan rutin mengadakan seminar untuk } \\
\text { meningkatkan kualitas sumber daya karyawan }\end{array}$ & 3,5 & Baik \\
\hline & Total Rata-Rata & & 3,8 & Baik \\
\hline \multirow[t]{7}{*}{4} & Pelanggan & $\begin{array}{l}\text { Anda merasa puas atas pelayanan } \\
\text { Perusahaan ini }\end{array}$ & 4 & Baik \\
\hline & & $\begin{array}{l}\text { Informasi mengenai barang yang } \\
\text { ditawarkan dapat diakses dengan } \\
\text { mudah oleh anda sebagai pelanggan }\end{array}$ & 3,8 & Baik \\
\hline & & $\begin{array}{l}\text { Anda puas dengan harga yang } \\
\text { ditetapkan perusahaan ini }\end{array}$ & 3,2 & Baik \\
\hline & & $\begin{array}{l}\text { Barang yang ditawarkan oleh perusahaan ini telah sesuai } \\
\text { dengan kebutuhan anda sebagai pelanggan }\end{array}$ & 3,6 & Baik \\
\hline & & $\begin{array}{l}\text { Komplain dari pelanggan langsung } \\
\text { ditangani oleh perusahaan }\end{array}$ & 3,2 & Baik \\
\hline & Total Rata-Rata & & 3,56 & Baik \\
\hline & & I Nilai Rata-Rata Seluruh Perspektif & $\mathbf{3 , 8 7}$ & Baik \\
\hline
\end{tabular}

Berikut ini didapatkan rata-rata skor rantai pasok PT. Sumber Alfaria Trijaya, Tbk (Alfamart) cabang Ciputat pada Tabel 10. 
Tabel 10 Rata-Rata Skor Rantai Pasok PT. Sumber Alfaria Trijaya, Tbk (Alfamart) cabang Ciputat di Jalan W.R Supratman

\begin{tabular}{lll}
\hline Perspektif & Rata-Rata Nilai & Keterangan \\
\hline Keuangan & 4 & Baik \\
Proses Bisnis & 4,15 & Sangat Baik \\
Pertumbuhan dan Pengembangan & 3,8 & Baik \\
Pelanggan & 3,56 & Baik \\
\hline Total & $\mathbf{3 , 8 7}$ & Baik
\end{tabular}

\section{KESIMPULAN}

Berdasarkan rekapitulasi hasil penelitian yang didapat dari rata-rata nilai yang diperoleh dari setiap perspektif berdasarkan metode balanced scorecard dengan perhitungan yang menunjukkan bahwa perspektif keuangan mendapatkan nilai 4 (baik), perspektif proses bisnis internal mendapatkan nilai 4,15 (sangat baik), perspektif pertumbuhan dan pengembangan mendapatkan nilai 3,8 (baik), dan perspektif pelanggan mendapatkan nilai 3,56 (baik). Sedangkan total nilai rata-rata untuk seluruh perspektif adalah 3,87 (baik). Dapat disimpulkan bahwa kinerja rantai pasok yang berada di PT. Sumber Alfaria Trijaya, Tbk berdasarkan empat perspektif balanced scorecard sudah baik, namun harus tetap ada upaya yang dilakukan oleh perusahaan untuk mempertahankan atau meningkatkan kinerja rantai pasok yang ada diperusahaan PT. Sumber Alfaria Trijaya, Tbk.

\section{REFERENSI}

[1] G. E. J. Nusale, J. V Mangindaan, and D. D. S. Mukuan, "Analisis Rasio Profitabilitas Pada Pt. Sumber Alfaria Trijaya, Tbk (Alfamart)," p. 9.

[2] C. Srimindarti, Balanced Scorecard Sebagai Alternatif untuk Mengukur Kinerja, vol. 3. Fokus Ekonomi.

[3] S. Yuwono, Petunjuk Praktis Penyusunan Balanced Scorecard: Menuju Organisasi yang Berfokus pada Strategi, 2007th ed. Jakarta: PT Gramedia Pustaka Utama.

[4] M. A. Pongoh, "Analisis Penerapan Manajemen Rantai Pasokan Pabrik Gula Aren Masarang," vol. 4 No.3, Sep. 2016.

[5] M. Robinson, e-Business 7.0: A Roadmap to Success. 2000.

[6] J. Heizer and B. Render, Operations Management (11th Edition) Sustainability and Supply Chain Management. .

[7] S. Chopra and P. Meindl, Supply Chain Management: Strategy, Planning, and Operation (6th Edition) by Sunil Chopra, Peter Meindl. .

[8] P. J. Knill and S. K. Levine, Principles and Practice of Expressive Arts Therapy. 2005.

[9] R. S. Kaplan and D. P. Norton, The Balanced Scorecard: Translating Strategy into Action. Boston: Harvard Business School Press, 1996.

[10] R. S. Kaplan and D. P. Norton, "Linking Strategy To Operations For Competitive Advantage," p. 323.

[11] D. I. Diana, R. Tawaf, and M. Paturochman, "Analysis Of Supply Chain Management Food Industries Sausage From Producent To Consument In Bandung,” p. 15.

[12] S. C. Wuwung, "Manajemen Rantai Pasokan Produk Cengkeh Pada Desa Wawona Minahasa Selatan," p. 9, 2013.

[13] B. Isma Putra, "Analisis Pengukuran Kinerja Dengan Metode Balance Scorecard (BSC) di CV MCH Sidoarjo," 2005.

[14] M. Mahsina, A. Poniwatie, and C. Cholifah, "Analisis Penerapan Balance Scorecard, Alat Ukur Penilaian Kinerja pada Dinas Pendapatan, Pengelolaan Keuangan, dan Aset Kabupaten Sidoarjo," J. Maksipreneur Manajemen, Koperasi, dan Entrep., vol. 7, no. 1, p. 59, Dec. 2017.

[15] V. Gasperz, Manajemen Kualitas: Penerapan Konsep-Konsep Kualitas Dalam Manajemen Bisnis Total. Jakarta: PT Gramedia Pustaka Utama, 1997.

[16] V. Devani, "Pengukuran Kinerja Perpustakaan Dengan Pendekatan Balanced Scorecard," J. Ilm. Tek. Ind., vol. 15, no. 1, pp. 27-35, 2016.

[17] N. Asnawi, "Pengukuran Usability Aplikasi Google Classroom Sebagai E-learning Menggunakan USE Questionnaire ( Studi Kasus : Prodi Sistem Informasi UNIPMA )," vol. 1, 
no. 2 , pp. $17-21,2018$

[18] U. Analysis, "Analisis dan Pengukuran Tingkat Ketergunaan ( Usability ) Penggunaan Website E-learning di Jurusan Ilmu Komputer Universitas Negeri Semarang," vol. 17, no. 2, pp. 171$178,2018$.

[19] J. Ilmu et al., "Kualitas pelayanan publik dalam pembuatan izin trayek oleh dllaj kabupaten bogor effectiveness of public service in service by dllaj route permits bogor district," vol. 2, no. April, pp. 47-59, 2016. 